\title{
Long Term Quality Enhancement and Learning Management through Virtual Teaching in Higher Education in Paschim Medinipur District
}

\author{
Sibsankar Mal ${ }^{1}$, Sandip Tripathy ${ }^{2}$ and Bikash Ghosh ${ }^{3}$ \\ ${ }^{1}$ Department of Geography, S.S.M. College, Keshpur, Paschim Medinipur, West Bengal, India \\ ${ }^{2}$ Department of Geography, Kharagpur College, Inda, Paschim Medinipur, West Bengal, India \\ ${ }^{3}$ Assisstant Teacher, Haridih Jr. High School, Purulia, West Bengal, India
}

\begin{abstract}
With the advent of Liberalization, Privatization and Globalization, the students of higher education are the vital Human Resources and playing a significant role to achieve a tremendous success in the development of a country. The teaching methodology which is used within a higher education course is an important ingredient in creating a course with soul-stirring interest to students. Today's competitive world demands good quality education. In order to fulfill the aspirations of the present day fast changing society, efficient resource management, development of quality of higher education are required which is possible by Virtual Learning. Virtual Learning provides good communication skills, teamwork, effective time management, critical appraisal skills, research ability, long term learning capacity, application and to sustain a quality culture as internal and organizational parameter as well as learning management. Many studies report the virtual learning environment as more effective, efficient and satisfying than the traditional learning situation. In Paschim Medinipur, higher education is faced with great challenges and difficulties. A recent study shows that, here the student community has least aspire to be empowered and endowed with knowledge, skills, application and competitiveness to compete in the global society. In this regard, virtual teaching would play a vital role in enhancing quality assurance and facilitating internalization of the quality education with sustenance the learning process.
\end{abstract}

Key words: Higher Education, Knowledge, Learning Management, Quality, Virtual teaching.

\section{Introduction:}

Education or teaching in the broadest sense is any act or experience that has a formative effect on the mind, character or physical ability of an individual. In its technical sense education is the process by which society deliberately transmits its accumulated knowledge, skills and values from one generation to another [7]. Higher education, also called tertiary, third stage, or post secondary education, is the non-compulsory educational level that follows the completion of a school providing a secondary education, such as a high school, secondary school [8]. Tertiary education is normally taken to include undergraduate and postgraduate education, as well as vocational education and training. Colleges and universities are the main institutions that provide tertiary education. Collectively, these are sometimes known as tertiary institutions. Tertiary education generally results in the receipt of certificates, diplomas, or academic degrees. Higher education is defined in the International Standard Classification of Education (ISCED) Handbook as -more specialized study normally undertaken after successful completion of a good basic education lasting for at least eleven years [2]. The term 'higher education' and 'further education' are variously understood. However, under the Education Act 1988, higher education is defined as higher courses in any institution broadly, those of a standard than the General Certificate of Education (G.C.E.). Higher education includes teaching, research and social services activities of universities, and within the realm of teaching, it includes both the undergraduate level (sometimes referred to as tertiary education) and the graduate (or postgraduate) level (sometimes referred to as graduate school) [4]. Higher education generally involves work towards a degree-level or foundation degree qualification [5]. Higher education is therefore very important to national economies, both as a significant industry in its own right, and as a source of trained and educated personnel for the rest of the economy [3].

Now a day, in Paschim Medinipur district the higher education system is in a conflict and confined form which is less effective for the students of higher education. The teaching processes, which are backdated and traditional, are also unable for improvement of standards of learning as well as knowledge. The conventional teaching methods do not serve the significant and applicable knowledge in today's competitive world. As a result the students are facing difficulties and have the least aspiration about their educational subject matter.

Virtual teaching is being created by organizing the learning environment in new ways, based on different technological configurations and field works for learning and communicating between peers and 
teachers [1]. As changing demographics, technological developments, and globalization, higher educational system requires individual adaptation and the renewal of educational systems and learning in the workplace in Paschim Medinipur. Therefore, universities and other higher education providers need to be more responsive to market forces and provide more flexible approaches to the education and training marketplace. The number of new virtual teaching environments (VTEs) is increasing and they have been advertised as being a solution for remote and cross-border education. Students can perform a wide range of exercises with a computer-based learning environment. This is extremely important when the tasks cannot be practiced in real life, for example due to their hazardous nature. Technical innovation in education in the form of "virtual teaching environments" is one possible solution, which could encourage greater access to cross-cultural education and promote educational development. Therefore, Virtual teaching would play a vital role in enhancing quality assurance and facilitating internalization of the quality education with sustenance the learning process of higher education in Paschim Medinipur district.

\section{Objectives Of The Study:}

1. To explore the teaching and learning process and trend of application.

2. To explore the Curriculum Structure of higher educational institutes and its impacts in long term learning and quality enhancement as well as management.

3. Exploring the learning stability in higher education and understanding of the student's learning academic about their knowledge practice in today's competitive world.

4. To inquire the curriculum development and enrichment of students in higher education and evaluate the effectiveness of the virtual teaching process in this regard.

3.1 Hypothesis Tested:

\section{Methodology:}

The set of hypotheses to be tested comprise the following

1. Whether the traditional teaching methods are selective with respect to time for enriching the student's knowledge in higher education?

2. Whether the traditional teaching methodologies are really alarming and have significant long term learning impacts?

3. Whether the teaching process of higher education can be modeled and applied?

4. Whether the teaching processes are changing with progressive socio economic aspect and qualitative education demand?

Keeping in view the objectives of the study, the descriptive and analytical survey method was chosen for the investigation for this study. The study was done with the following ways:
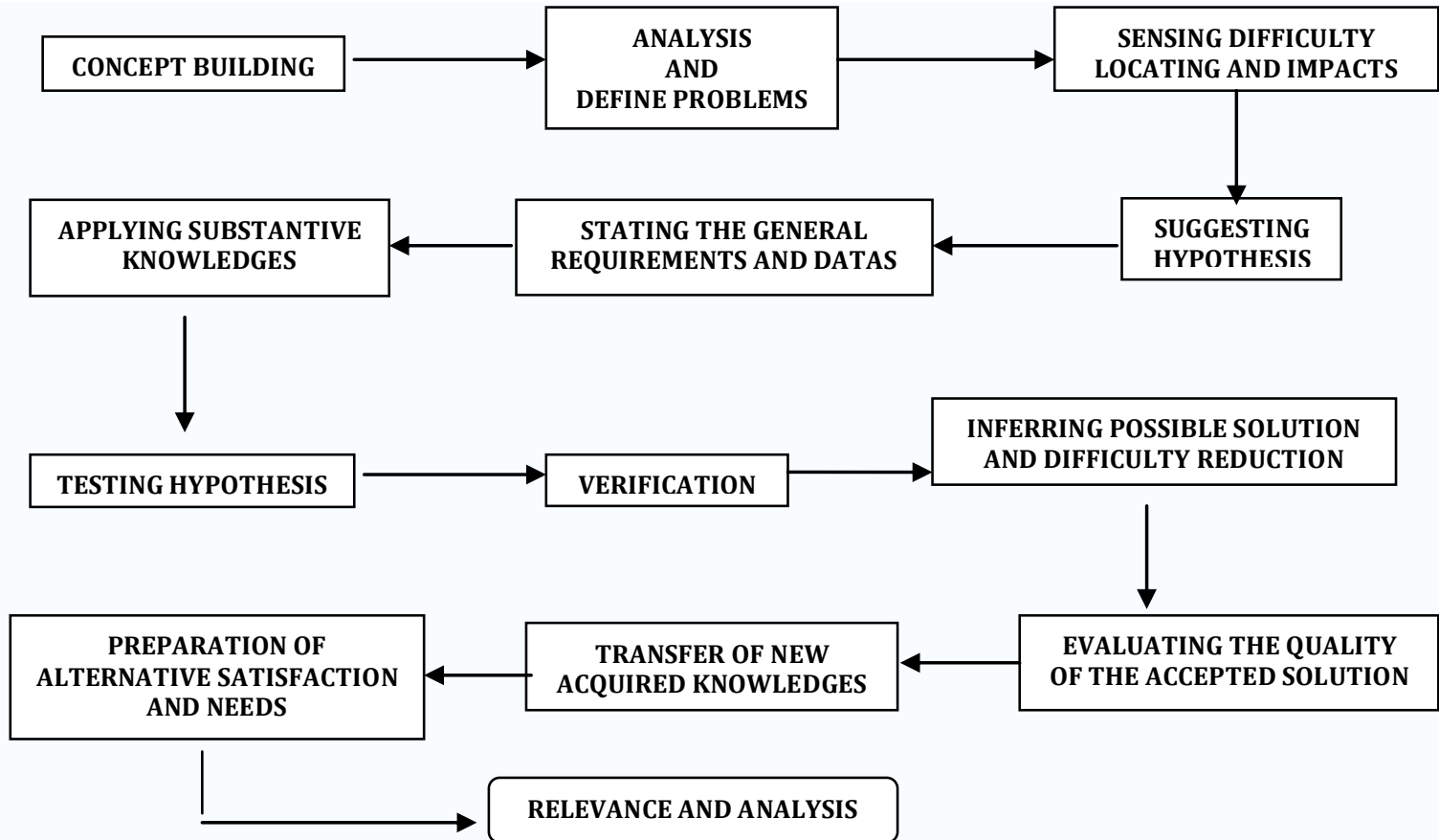

\subsection{Study Area:}

Paschim Medinipur is an important district of West Bengal and is located in the southwestern side. The area of Paschim Medinipur is 9295.28 sq. km and the amount of population is 5193411(Census 2001) with 
70.41\% literacy rate (2001). This district has 29 blocks which are classified with 4 major sub-divisions (Midnapur Sadar, Kharagpur sub-division, Jhargram sub-division, Ghatal sub-division).

\subsection{Material:}

The study was based on analytical observation and group discussion with the students of colleges and university. For the study, 50 in-depth interviews with college students, 35key-informant interviews, and 24 focus-group discussions along with extensive field observations, were conducted. Research methods were used for blending qualitative data-collection methods to obtain a detailed and reliable picture of the higher education system of the district. We incorporated opinions of key-informants for validating data collected from other secondary sources. The research design, research process, and concepts used in this study can be used for comparative studies in other settings. Peer debriefing, participatory interpretations with participants, and intersubjective understanding of findings among the members of the research team have contributed to the dependability of the findings presented in this article.

\section{Results:}

The results of the study are discussed through the following heads-

\subsection{Characteristics of education and literacy of Paschim Medinipur District:}

Medinipur district is one of the developed districts of West Bengal in education. According to the 2001 census the literacy rate in Medinipur district has been $75.2 \%$ just after Kolkata, North 24 Parganas, Howrah and Hooghly. The said rate for Paschim Medinipur district was slightly lower at 70.4\%. Literacy rates for the district in rural and urban areas and for male and female population are given in Table1. Though the overall literacy rate of the district is above $70 \%$ the picture is slightly gloomy in the western part of the district i.e. Jhargram Subdivision and certain parts of Medinipur Sadar Sub-division. These areas are mainly dominated by scheduled tribes and primitive tribal groups who remain economically and educationally backward for over the years. Two blocks of Jhargram Sub-division viz. Nayagram and Gopiballavpur-I are considered as Educationally Backward Block (EBB) on the basis of its low female literacy percentage [10]. It may be mentioned here that apart from these two declared EBBs there are some more blocks which are very close to these EBBs by character. Female education is enough linked with the human development and it is a strong predictor of socioeconomic, demographic and health status of a region. The simplest indicator to measure it is obviously the female literacy rate. Higher the value of female literacy rate better is the district, i.e. higher the Index value.

TABLE 1: Educational Status in Paschim Medinipur District, 2001

\begin{tabular}{|l|l|l|l|l|l|l|l|l|l|l|}
\hline \multicolumn{1}{|c|}{$\begin{array}{c}\text { Sub } \\
\text { Division }\end{array}$} & $\begin{array}{c}\text { Litera } \\
\text { cy } \\
\text { Rate } \\
\text { Total }\end{array}$ & $\begin{array}{c}\text { Male } \\
\text { Litera } \\
\text { cy } \\
\text { Rate }\end{array}$ & $\begin{array}{c}\text { Femal } \\
\mathbf{e} \\
\text { Litera } \\
\mathbf{c y} \\
\text { Rate }\end{array}$ & $\begin{array}{c}\text { Gend } \\
\text { er } \\
\text { Gap }\end{array}$ & $\begin{array}{c}\text { Rural } \\
\text { Litera } \\
\text { cy } \\
\text { Rate }\end{array}$ & $\begin{array}{c}\text { Urban } \\
\text { Litera } \\
\text { cy } \\
\text { Rate }\end{array}$ & $\begin{array}{c}\text { Rural } \\
\text { Male } \\
\text { Litera } \\
\text { cy } \\
\text { Rate }\end{array}$ & $\begin{array}{c}\text { Rural } \\
\text { Femal } \\
\mathbf{e} \\
\text { Litera } \\
\text { cy } \\
\text { Rate }\end{array}$ & $\begin{array}{c}\text { Urban } \\
\text { Male } \\
\text { Litera } \\
\text { cy } \\
\text { Rate }\end{array}$ & $\begin{array}{c}\text { Urban } \\
\text { Femal } \\
\mathbf{e} \\
\text { Litera } \\
\text { cy } \\
\text { Rate }\end{array}$ \\
\hline Ghatal & 75.10 & 64.80 & 60.20 & 24.60 & 74.00 & 81.90 & 84.10 & 64.00 & 89.60 & 73.80 \\
\hline Jhargram & 63.50 & 76.70 & 49.70 & 27.00 & 62.20 & 84.80 & 75.80 & 48.10 & 90.90 & 78.40 \\
\hline $\begin{array}{l}\text { Kharagpu } \\
\text { r }\end{array}$ & 73.50 & 83.90 & 62.60 & 21.30 & 72.10 & 81.30 & 83.10 & 60.60 & 87.90 & 74.20 \\
\hline $\begin{array}{l}\text { Medinipur } \\
\text { Sadar }\end{array}$ & 67.50 & 78.10 & 56.30 & 21.80 & 64.90 & 84.10 & 64.90 & 52.80 & 89.00 & 79.00 \\
\hline District & 70.40 & 81.30 & 59.10 & 22.20 & 68.70 & 82.40 & 68.70 & 56.80 & 88.70 & 75.70 \\
\hline
\end{tabular}

Source: Census-2001, Paschim Medinipur.

\subsection{Characteristics of Higher Education in Paschim Medinipur District:}

Although the literacy rate of Paschim Medinipur is rather better than other districts, but the academic system in higher education is not so good. The teaching and learning procedures are backdated and are practicing by merging the conventional way of teaching -learning process with modern techniques to some extent (e.g. use of computers and internet, seminars, research and field works etc). And because of these cumulative dangerous consequences, the quality of the students and their memory about their specific subject are deteriorating day by day. In Paschim Medinipur, there are many higher education institutes; but among of them Kharagpur IIT and the Vidyasagar University are practicing the virtual type teaching methods to medium extent and are receiving a better result. Table 2 represents the numbers of institutes of higher education in Paschim Medinipur. 
TABLE 2: Various Institutes of Higher Education in Paschim Medinipur District.

\begin{tabular}{|l|c|}
\hline \multicolumn{1}{|c|}{ Types of institute } & No. \\
\hline Degree colleges (arts, science \& commerce) & 26 \\
\hline University (Vidyasagar University) & 1 \\
\hline IIT (Kharagpur) & 1 \\
\hline Medical colleges & 5 \\
\hline Art college (Midnapur) & 1 \\
\hline Law college (Midnapur) & 1 \\
\hline ITI & 2 \\
\hline Polytechnique college (Jhargram) & 1 \\
\hline Engineering college (Chandrakona) & 1 \\
\hline N.S.O.University study centre & 6 \\
\hline I.G.N.O.U study centre & 1 \\
\hline R.B.University distance study centre & 2 \\
\hline B.Ed college & 5 \\
\hline
\end{tabular}

\subsection{Problems of Traditional Teaching Methods and Higher Education System:}

There are high amount of problems and difficulties due to traditional teaching processes and other remarkable associated factors in the institutes of higher education in Paschim Medinipur. These are classified in four major groups: -

\section{Academic}

- Lack of proper academic environment.

- Defective examination system.

- Bookish and uninspiring curriculum.

- Rise in tuition fees.

- Lack of individual contact between the teacher and the taught.

- Defective admission and attendance rules.

- Lack of motivation among students.

- Lack of computer and internet knowledge.

- Least knowledge about seminars, project works, field surveys etc.

- Lack of visual knowledge about subject.

- Lack of application of learning knowledge.

- Students are learning their subjects for taking good marks without proper understanding and accumulation of their subject knowledge.

- High dependency on private tuition due to insufficient teaching-learning processes.

- Maximum students have the afraid mentality to study their subject in English version.

- Lack of teaching and learning management.

\section{Administrative:}

- Double standards of the authorities and corruption at the highest echelons of administration.

- Lack of sympathy for students.

- Non involvement of students in university affairs.

\section{Political:}

- Political interference in admissions appointments etc.

- Political interference in union elections.

\section{General:}

- Lack of ideals of the society.

- Lack of commitment on the part of university teachers.

- Teachers in fighting.

- Ideological frustration.

- Lack of respect for authority - parental, governmental and educational.

- Lack of employment opportunities. 


\section{Discussion And Analysis}

\subsection{Appropriate Integrated Planning For Higher Education:}

In this district, besides from some regional limitation, the Virtual Teaching process is given the consideration on its merits, would be the right path to retain the good learning assessment as well as the quality of long term knowledge enhancement. The virtual teaching method has the potential to transfer teaching process as the main tool for education conservation. The functions of virtual teaching are: -

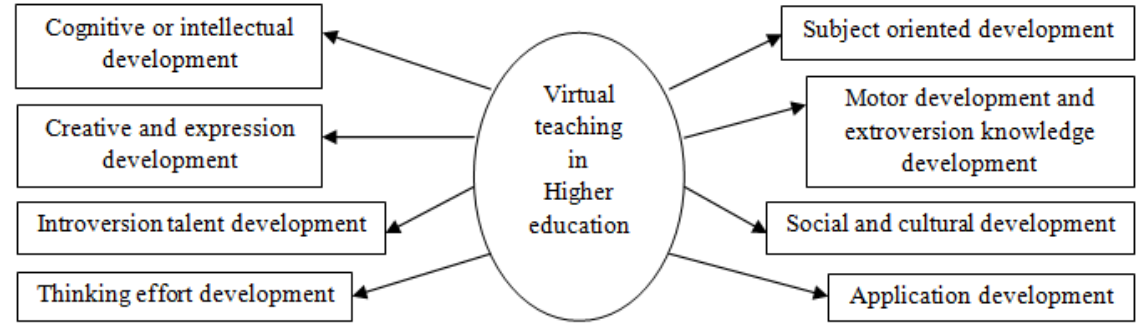

The concept of virtual teaching has three types of mechanism: -

a. Role making :

- Self role integration: - enjoying the role and thinking that it is according to liking, training and aptitude.

- Creativity: - innovating or doing new things.

b. Role centering:

- Confrontation: - confronting and solving conflicts or problems.

- Centrality: - perceiving importance.

- Influence: - exercising influence for making his/her advice as accepted.

- Personal growth: - perceiving the role as providing opportunities for personal growth.

c. Role linking:

- Inter role linkage.

- A helping relationship.

\subsection{Priority Roles of Virtual Teaching Methodology:}

The virtual teaching process minimizes the teaching-learning conflicts and associated difficulties with sustainable development of education through its effective roles: -

1. Expand subject information

2. Develop skill in location reading materials on particular topics

3. Increase the ability to distinguish between fact and opinion.

4. Develop the ability to make valid generalizations.

5. Increases faith in the democratic process.

6. Make informed decisions about teaching and support of learning.

7. Draw on a repertoire of methods of assessment and giving feedback to learners.

8. Explore the relationship between their teaching and their research.

9. Articulate their own educational values relating to equality and diversity, and reflect on their relation to the values of professional bodies.

10. Explore different disciplinary traditions and practices in learning, teaching and assessment.

11. Analyze the students' accounts of their own learning in relation to theoretical approaches to learning.

12. Encourages contact between students and faculty,

13. Develops reciprocity and cooperation among students,

14. Encourages active learning,

15. Carry out a sustained inquiry into an aspect of their professional practice.

16. Work effectively within the academic learning community.

17. Make informed decisions about the design and planning of learning activities and/or programs of study.

18. Consider the development of effective learning environments and learner support systems in their discipline.

19. Demonstrate their reflective practice and professional development.

20. New modes of teaching (e.g. team-teaching, pair-teaching, collaborative teaching).

21. Production of new knowledge in different pedagogical models.

22. Assessment of student learning (student-centric activities of self-assessment, reflection, career portfolios, etc.). 
23. The contribution of the environment and the technology for the enhancement of the teaching and the learning.

24. Increase internal incentives in the development of quality teaching initiatives and of quality culture.

25. Exploring relevant evaluation methods and assessing the impacts.

\subsection{Implementing Pedagogical Strategy of Virtual Teaching:}

In Paschim Medinipur, the pedagogical strategies of virtual teaching-learning processes should more

effective and significant for learning management. These are the following: -

1. Virtual teaching environments are fundamentally similar to learning environments which can be defined as "A place or community arranged specifically for learning purposes and mediated by the intensive use of ICT, and one that is based on ideas of the structure of knowledge and learning, and the practical arrangements necessary for learning connected with time, place and repetitive rituals which together provide the social organization for learning and teaching." $[2]$

2. The main components of learning environments that enable learning to take place are: -

a) Pedagogical functions - learning activities and materials, tutoring, teaching situations and evaluation.

b) Appropriate Information and Commutation Technologies - suited to a pedagogical model.

c) Social organisation of education - time, place and community.

3. Virtual teaching environments tend to be introduced parallel to other forms of study, but this raises concern about their sustainability.

4. Market pressures are more evident than political pressure when implementing virtual teaching environments in institutions.

5. Yet financial priorities, perceptions of the university's role and arrangements for learning and assessment inhibit institutions from totally embracing virtual teaching environments.

6. Virtual teaching environments make access to more students and client populations possible although some tutors found it hard to monitor learner's satisfaction.

7. However, virtual teaching environments could improve the current quality/variety of teaching/learning and reduce the administrative burden on teachers.

8. Virtual teaching environments are also considered to be new sources of income or reduce current costs for institutions.

9. Some academics consider virtual teaching environments as a way of enhancing their reputation and career potential.

10. Barriers to the implementation of virtual teaching environments include faculty members' resistance to change; funding; lack of adequate facilities and no priority over other users.

11. Telecommunications infrastructure is improving along with the available bandwidth and with the availability of low cost powerful computers and software suites virtual learning environments are technologically and economically accessible.

\subsection{Recommendations of Virtual teaching technique in Paschim Medinipur District:}

Recommendations include adopting the following approaches to implementing virtual teaching environments: -

\subsubsection{Policy recommendations at institutional level:}

1. The initiation of virtual teaching environments requires a process of the development, circulation and discussion of an initial Green Paper, which is then revised for implementation.

2. Factors to be considered when planning virtual learning environments include information selection and design, communication, organisational management, technological realisation, and didactics.

3. The three key factors underlying any virtual teaching environment implementation policies include infrastructure, training and development and organisational culture.

4. However, the implementation of virtual teaching environments will not succeed without an equal integrated and coordinated investment in all three of these elements.

5. The change to be brought about by virtual teaching environment implementation requires an "organisational development" approach in which resource management, professional development and objective sharing are the key components.

6. Professional development programs and overt institutional support structures must be developed to elevate the status of "research in teaching" and therefore facilitate the diffusion of virtual teaching environments innovations.

7. In order to adopt virtual teaching environments, institutions can use a number of events and communication systems to consult any of the following stakeholders - professional bodies; staff/student associations; government funding bodies; any bodies associated with the administration of the state or the region that might have an interest in the development of the university and national government relating to learning. 


\subsubsection{Teaching/Learning policy recommendations:}

The following recommendations require both the teacher and the learner to be set in their academic,

social and cultural contexts.

8. Teachers need special training for online-education. Teaching in virtual learning environments needs competence in technological (so-called hard skills) and organisational aspects as well as new skills in applying relevant didactical methods, moderating/facilitating, etc.

9. Support is needed for the development of "innovation units", (consisting of technical groups, academic departments and teams of teachers) to work towards changing teaching practice.

10. The potential of technological tools must be balanced with an institution's pedagogical model.

11. Learning resources and materials must be specifically designed for virtual learning environments.

12. The division of labor for tutors, lecturers and other staff involved in learning campus operations needs to recognize the difference in virtual teaching environments workloads.

\subsubsection{Cross-cultural policy recommendations:}

The following recommendations are designed to protect cultural minorities and those who prefer to

learn through their mother tongue.

13. The use of virtual teaching environments needs to be promoted through collaboration at district level and vice versa.

14. International virtual teaching environment activities demonstrate legal and economic problems, and highlight the differences in the learning patrimonies of the audiences. Financial considerations also need to be addressed.

\section{Conclusion}

This paper has proposed that there would be advantages in the University and the college teaching profession acting as a learning community by sharing experiences and exchanging good practice through virtual teaching methodology. As a mechanism for higher education, it is suggested that virtual teaching -learning activities can develop the student's needs and manage the educational system with enriching the student's quality than traditional teaching process in Paschim Medinipur. The limitation of the study is that the field of virtual teaching evolves so rapidly that some of the results may soon be obsolescent. This could be especially likely for this research since it concentrates on implementation (and to some extent the early adoption phase), a phase in which practices have not been institutionalized. The basic assumption of the research was that sociocultural, institutional/organizational, and teaching/learning factors are interrelated in the practices of the educational actors and in the institutional culture as a whole in the virtual teaching experiences. We cannot separate any one dimension, because each element separately as well as the combination of all of them together has a critical effect on the results of the implementation of educational environment as a whole. Educators and educational institutions need to understand that virtual worlds, like other social media, are here to stay and that these exciting forms of media are not a threat to formal education. The genuine conversation and participation that virtual worlds encourage is a step toward more authentic learning for all students.

\section{References}

[1]. Barajas M. et alt. (1998).Virtual Classrooms in Traditional Universities: Changing Teaching Cultures through Telematics. World Congress ED-MEDIA/ED-TELECOM. Freiburg, 20-25 June 1998.

[2]. Barajas, M., Owen, M. (2000). Implementing Virtual Learning Environments. Looking for a Holistic Approach. Educational Technology \& Society 3(3), 39-53.

[3]. European Commission (1993), White Paper on growth, competitiveness, and employment: The challenges and ways forward into the 21st century. Available at http://europa.eu.int/en/record/white/c93700/contents.html (10-06-2002)

[4]. Henderikx, P., Hoff, F., Hardy, D. (2000). European Virtual Universities in Context. In New Learning: Invited Articles of the Conference "ODL Networking for Quality Learning". Ed. A. R.Trindade. Lisbon: Universidade Aberta, 285-327.

[5]. Oilo, D. (1988). From traditional to virtual: the new information technologies. UNESCO,

[6]. October 1998: http://www.unesco.org/education/educprog/wche/principal/nit-e.html.

[7]. Kochhar, S.K. (2007) Secondary School Administration.

[8]. Kochhar, S.K. (2007), Methods and Techniques of Teaching.

[9]. Paschim Medinipur District Statistical Handbook, Government of West Bengal

[10]. District Human Development Report, Paschim Medinipur, 2011, Government of West Bengal. 